\title{
Vitamin A deficiency among under-five Nigerian children with diarrhoea
}

\author{
Olufunmilola O Abolurin ${ }^{1}$, Adebanjo J Adegbola ${ }^{2}$, Oyeku A Oyelami ${ }^{1}$, Samuel A Adegoke ${ }^{1}$, Oluseye O Bolaji ${ }^{2}$
}

1. Department of Paediatrics, Obafemi Awolowo University Teaching Hospitals Complex, Ile-Ife, Nigeria.

2. Faculty of Pharmacy, Obafemi Awolowo University, Ile-Ife, Nigeria.

\section{Emails:}

1. Olufunmilola O Abolurin: funlyt@yahoo.com

2. Adebanjo J Adegbola: banjogbola@yahoo.com

3. Oyeku A Oyelami: oyekuoyelami@gmail.com

4. Samuel A Adegoke: adegoke2samade@yahoo.com

5. Oluseye O Bolaji: obolaji@oauife.edu.ng

\section{Abstract}

Background: Vitamin A deficiency (VAD) and diarrhoea are still important contributors to childhood deaths in Africa, and vitamin A deficient children are at increased risk as well as severity of diarrhoea.

Objectives:To determine the prevalence of VAD and identify the associated factors among children with diarrhoea.

Methods: The study was a hospital-based cross-sectional descriptive study. Consecutive children with diarrhoea were recruited, provided they met the inclusion criteria. Serum retinol levels were determined by high performance liquid chromatography (HPLC) in one hundred and seventy under-five children who presented with diarrhoea at the Wesley Guild Hospital, Ilesa, Nigeria.

Results: The serum retinol levels of the children ranged from $0.29-2.35 \mu \mathrm{mol} / \mathrm{L}$ with a mean \pm SD of $1.07 \pm 0.42 \mu \mathrm{mol} / \mathrm{L}$. Twenty seven (15.9\%) were vitamin A deficient with three (1.8\%) of these having severe VAD. Wasting was significantly associated with a higher prevalence of VAD $[\mathrm{p}=0.023$, OR $(95 \% \mathrm{CI})=3.08(1.21-7.79)]$. A significantly greater proportion of the subjects who had VAD were hospitalized, compared with the non-deficient ones $[\mathrm{p}=0.001$, OR $(95 \% \mathrm{CI})=4.40(1.82-10.66)]$. The only subject who died was vitamin A deficient.

Conclusion: Wasting and hospitalization are factors that may indicate the presence of VAD in a child with diarrhoea. Vitamin A supplements should therefore be given, as part of the treatment for diarrhoea, to children who have wasting, especially when they require hospitalization.

Keywords: Vitamin A deficiency, Nigerian children, diarrhoea.

DOI: https://dx.doi.org/10.4314/ahs.v18i3.32

Cite as: Abolurin OO, Adegbola AJ, Oyelami OA, Adegoke SA, Bolaji OO. Vitamin A deficiency among under-five Nigerian children with diarrboea. Afri Health Sci. 2018;18(3): 737-742. https://dx.doi.org/10.4314/abs.v18i3.32

\section{Corresponding author:}

Olufunmilola O Abolurin,

Department of Paediatrics, Obafemi Awolowo

University Teaching Hospitals complex,

Ile-Ife, Nigeria;

Tel: ; +2348035176432

Email: funlyt@yahoo.com

\section{Introduction}

Vitamin A deficiency (VAD) and diarrhoea are both renowned for their significant contributions to childhood deaths in Africa. Vitamin A deficiency has been reported to be responsible for almost six percent of under-fivedeaths in Africa, ${ }^{1,2}$ while diarrhoea contributes at least 10 percent. $^{3} \mathrm{~A}$ link has been established between VAD and childhood diarrhoea, with a related risk of a fatal disease 
outcome. In fact, vitamin A-deficient children have been found to be at increased risk and severity of diarrhoeal disease. $^{4,5}$

Vitamin A plays an important role in the maintenance of epithelial linings and is therefore essential for the regeneration of damaged mucosal epithelial cells in the body. ${ }^{6,7}$ As a result of damage to the intestinal epithelial tissues, diarrhoea increases the body's requirements for vitamin A, thereby exerting a drain on the body reserve of the vitamin. ${ }^{6,8}$ Worse still, absorption of the vitamin is reduced and its loss increased during diarrhoea. ${ }^{8-10}$

Most studies on vitamin A focus on the deficiencies of the vitamin in the general population of children, while studies specific to children with diarrhoeal diseases are uncommon, particularly in developing countries.

Periodic vitamin A supplementation has been found to reduce the severity of diarrhoeal episodes as well as the overall under-five mortality rate. ${ }^{11-13}$ However, vitaminA supplementation as treatment for diarrhoea has been found to be useful only for children who are vitamin A deficient. ${ }^{14,15}$ Identification of such children is usually difficult in clinical settings in most developing countries where vitamin A assay is not easily accessible and cannot be readily done on demand. This may undermine the usefulness of the intervention, as failure to identify deficient children may result in depriving them of the life-saving treatment.

Identification of factors that indicate VAD among children with diarrhoea may thus help to combat this problem such that high-risk children are made to receive vitamin A supplements as part of their treatment for diarrhoea. This would help to improve their treatment outcome and overall chances of survival. This study was therefore carried out to determine the prevalence of VAD and identify the associated factors among children with diarrhoea.

\section{Methods}

The study was a hospital-based cross-sectional descriptive study. Children aged between six months and five years, who presented with diarrhoea, were recruited at the under-five welfare clinic and the chilldren's emergency ward of the Wesley Guild Hospital, Ilesa. The Hospital is one of the units of the Obafemi Awolowo University Teaching Hospitals Complex (OAUTHC), Ile-Ife, Osun State, Nigeria. Diarrhoea was defined as passage of three or more episodes of loose or watery stools in the preceding 24 hours. Consecutive children with diarrhoea were recruited, provided they met the inclusion criteria. Ethical clearance for the study was obtained from the Ethics and Research Committee of the OAUTHC, Ile-Ife, Nigeria. A total of 170 children with diarrhoea were studied. Children who had received vitamin A supplements within the previous four weeks, as well as those who had clinical conditions such as measles, pneumonia, sepsis that could influence vitamin A levels were excluded from the study. Informed consent was obtained from the parent/guardian before recruiting each child.

Details of the diarrhoeal illness, socio-economic background, breastfeeding history, immunization history, axillary temperature and anthropometric measurements, were obtained for each child. The children were also examined for signs of dehydration as well as for eye signs of vitamin A deficiency, including Bitot's spots, conjuctival and/or corneal xerosis, corneal clouding and corneal ulcers/scars. When present, the degree of dehydration was classified as mild, moderate or severe according to 'the guide to clinical assessment of dehydration'. ${ }^{16}$ Eye examination was done with the aid of a pen torch to provide illumination, while the eyelids were gently separated. The nutritional status of each child was derived from his/ her anthropometric measurements using the WHO child growth standards in form of z-scores. ${ }^{17}$ The children were classified into those from high and low social class based on the occupation and highest educational attainments of the parents. ${ }^{18}$ They were also classified into those who required hospital admission for treatment and those managed as out-patients. For those hospitalized, the outcome was documented as survived or died.

Blood samples were collected by venepuncture before the commencement of treatment. The blood samples were allowed to clot, after which centrifugation was done at 3000 revolutions per minute for 10 minutes in order to separate the serum. Serum retinol levels were determined by reversed-phase high performance liquid chromatography (HPLC), using retinyl acetate as internal standard. An 
Agilent 1100 series ${ }^{\circledR}$ HPLC machine (Agilent Technologies, Palm Alto, U.S.A.) fitted with a quaternary pump and a diode array UV detector (DAD) was used for the analysis. Serum electrolytes, urea and creatinine, as well as other necessary investigations were also carried out for children who required hospital admission. Electrolyte derangements were noted and corrected when present.

VAD was defined as serum retinol level less than $20.0 \mu \mathrm{g} /$ $\mathrm{dl}(0.70 \mu \mathrm{mol} / \mathrm{L})$, while severe VAD was defined as a value less than $10.0 \mu \mathrm{g} / \mathrm{dl}(0.35 \mu \mathrm{mol} / \mathrm{L})$. Data was analyzed using the statistical programme for social sciences (SPSS) version 17.0. Means and proportions were compared using the independent samples t-test $(\mathrm{t})$ and the Pearson chi-square test $(\chi 2)$, respectively. Logistic regression analysis (B) was done to determine factors independently associated with VAD. Probability values (p) less than 0.05 and $95 \%$ confidence intervals excluding unity were accepted as statistically significant.

\section{Results}

Of the 170 children studied, 91 (53.5\%) were males, while $79(46.5 \%)$ were females. Their ages ranged between 6 and 59 months with a mean of $16.6 \pm 10.0$ months. One hundred and forty six $(85.9 \%)$ children were aged 24 months and below, while $24(14.1 \%)$ were older than 24 months. Twenty five $(14.7 \%)$ belonged to the high social class, while the remaining 145 (85.3\%) were from low social class.

The duration of diarrhoea ranged from 1 to 21 days with a mean of $3.6 \pm 3.4$ days. The duration was $\leq 7$ days in 160 (94.1\%), 8-13 days in five (2.9\%) and $\geq 14$ days in another $5(2.9 \%)$ of the children. The number of episodes of watery stool per day ranged from 3 to 15 with a mean of $4.6 \pm 1.9$. One hundred and thirty five $(79.4 \%)$ children had 3-5 episodes per day, 27 (15.9\%) had 6-9 episodes and $8(4.7 \%)$ had $\geq 10$ episodes per day. Stool was bloody in eleven $(6.5 \%)$ children. A history of fever was present in 117 (68.8\%), while 55 (32.4\%) were febrile. One hundred and four $(61.2 \%)$ of the children had one or more episodes of vomiting, while reduction in urinary output was reported in nine $(5.3 \%)$ children. One hundred and twenty one $(71.2 \%)$ children had no evidence of dehydration while $29(17.1 \%)$ had mild, $16(9.4 \%)$ moderate, and $4(2.4 \%)$ severe dehydration.

Immunization status was appropriate for age in 142
$(83.5 \%)$ of the children, while $26(15.3 \%)$ had incomplete immunization and two $(1.2 \%)$ were not immunized at all. Ninety nine $(58.2 \%)$ children were still breastfeeding, while the remaining $71(41.8 \%)$ had been weaned. Twenty five $(14.7 \%)$ children were underweight, 31 (18.2\%) stunted and $29(17.1 \%)$ had wasting. No eye signs of VAD were identified in any of the children during eye examination. Thirty four $(20.0 \%)$ of the children required hospital admission either because of severe dehydration or for other reasons such as persistent vomiting, febrile convulsion or prostration. Seventeen $(50.0 \%)$ of the 34 children who were hospitalized had electrolyte derangements.

The serum retinol levels of the children ranged from $0.29-2.35 \mu \mathrm{mol} / \mathrm{L}$ with a mean $\pm \mathrm{SD}$ of $1.07 \pm 0.42$ $\mu \mathrm{mol} / \mathrm{L}$. Twenty seven $(15.9 \%)$ children were vitamin A deficient with three $(1.8 \%)$ of these having severe VAD. There was no significant correlation between age and serum retinol levels $(r=0.06, p=0.422)$. Table I shows the relationships between various characteristics and VAD. Sex did not significantly influence the VAD status $\left(\chi^{2}=\right.$ $1.07, p=0.302)$. Similarly, the prevalence of VAD did not show statistically significant variation with age-group $(\mathrm{p}=$ $0.375)$ or social class $(\mathrm{p}=0.375)$.

As shown in Table I, the prevalence of VAD had no significant relationship with immunization status $(\chi 2=0.92$; $p=0.633)$, stool frequency $\left(\chi^{2}=2.92 ; p=0.232\right)$, persistent diarrhoea $\left(\chi^{2}=1.82 ; \mathrm{p}=0.402\right)$, dysentery $(\mathrm{p}=$ $0.687)$, presence of fever $\left(\chi^{2}=2.40 ; p=0.122\right)$, or the presence of dehydration $\left(\chi^{2}=1.06, p=0.304\right)$. Furthermore, the severity of dehydration did not significantly influence the prevalence of VAD $\left(\chi^{2}=2.78, \mathrm{p}=0.249\right)$. Among the 146 children aged 24 months and below, the prevalence of VAD did not differ significantly between those who were still breastfeeding, in addition to taking family diet, and those who had stopped breastfeeding $(\chi 2=1.93, p=0.165)$. Wasting was significantly associated with a higher prevalence of $\operatorname{VAD}$ [OR $(95 \% \mathrm{CI})=$ $3.08(1.21-7.79) ; \mathrm{p}=0.023]$, whereas, underweight status $\left(\chi^{2}=1.45 ; \mathrm{p}=0.229\right)$ and stunting $(\mathrm{p}=0.788)$ were not. A significantly greater proportion of the subjects who had VAD were hospitalized, compared with the non-deficient ones [OR $(95 \% \mathrm{CI})=4.40(1.82-10.66) ; \chi^{2}=$ $11.99, \mathrm{p}=0.001]$. Among the 34 subjects that were hospi- 
talized, the prevalence of dyselectrolytaemias was not significantly different between the vitamin A deficient and the non-deficient ones $(\chi 2=2.06, p=0.151)$. The only subject who died was vitamin A deficient.
On logistic regression analysis, hospitalization had significant independent association with VAD [OR (95\% CI) $=0.28(0.11-0.71) ; \mathrm{p}=0.008]$, whereas wasting did not $(\mathrm{p}=0.181)$.

Table 1: Relationships between various characteristics and vitamin A deficiency.

\begin{tabular}{|c|c|c|c|}
\hline Characteristic & Vitamin A status & & Statistical significance (p) \\
\hline & VAD n $(\%)$ & Normal n $(\%)$ & \\
\hline \multicolumn{4}{|l|}{ Sex } \\
\hline Male & $12(13.2)$ & $79(86.8)$ & $\chi^{2}=1.07, \mathrm{p}=0.302$ \\
\hline Female & $15(19.0)$ & $64(81.0)$ & \\
\hline \multicolumn{4}{|l|}{ Age-group } \\
\hline$\leq 24$ months & $25(17.1)$ & $\begin{array}{l}121(82.9) \\
22(917)\end{array}$ & \\
\hline$>24$ months & $2(8.3)$ & $22(91.7)$ & ${ }^{*} \mathrm{p}=0.375$ \\
\hline \multicolumn{4}{|l|}{ Social class } \\
\hline High & $2(8.0)$ & $23(92.0)$ & $*_{\mathrm{p}}=0.375$ \\
\hline Low & $25(20.0)$ & $120(82.8)$ & \\
\hline \multicolumn{4}{|l|}{ Stool frequency } \\
\hline 3-5 episodes/day & $22(16.3)$ & $113(83.7)$ & \\
\hline 6-9 episodes/day & $5(18.5)$ & $22(81.5)$ & $\chi^{2}=2.92, \mathrm{p}=0.232$ \\
\hline$\geq 10$ episodes/day & $0(0.0)$ & $8(100.0)$ & \\
\hline \multicolumn{4}{|l|}{ Duration of diarrhoea } \\
\hline 1-7 days & $24(15.0)$ & $136(85.0)$ & \\
\hline 8-14 days & $2(40.0)$ & $3(60.0)$ & $\chi^{2}=1.82, \mathrm{p}=0.402$ \\
\hline$\geq 14$ days & $1(20.0)$ & $4(80.0)$ & \\
\hline \multicolumn{4}{|l|}{ Type of diarrhoea } \\
\hline Dysentery & $2(18.2)$ & $9(81.8)$ & $*_{\mathrm{p}}=0.687$ \\
\hline Non-bloody diarrhoea & $25(15.7)$ & $134(84.3)$ & \\
\hline \multicolumn{4}{|l|}{ Degree of dehydration } \\
\hline Mild dehydration & $4(13.8)$ & $25(86.2)$ & \\
\hline Moderate dehydration & $4(25.0)$ & $12(75.0)$ & $\chi^{2}=2.78, p=0.249$ \\
\hline Severe dehydration & $2(50.0)$ & $2(50.0)$ & \\
\hline \multicolumn{4}{|l|}{ Presence of fever } \\
\hline Yes & $22(18.8)$ & $95(81.2)$ & $\chi^{2}=2.40, p=0.122$ \\
\hline No & $5(9.4)$ & $48(90.6)$ & \\
\hline \multicolumn{4}{|l|}{ Breastfeeding status } \\
\hline Still breastfeeding & $14(14.1)$ & $85(85.9)$ & $\chi^{2}=1.93, p=0.165$ \\
\hline No longer breastfeeding & $11(23.4)$ & $36(76.6)$ & \\
\hline \multicolumn{4}{|l|}{ Immunization status } \\
\hline Appropriate for age & $22(15.5)$ & $120(84.5)$ & \\
\hline Incomplete & $5(19.2)$ & $21(80.8)$ & $\chi^{2}=0.92, \mathrm{p}=0.633$ \\
\hline None & $0(0.0)$ & $2(100.0)$ & \\
\hline \multicolumn{4}{|l|}{ Underweight } \\
\hline Yes & $6(24.0)$ & $19(76.0)$ & $\chi^{2}=1.45, p=0.229$ \\
\hline No & $21(14.5)$ & $124(85.5)$ & \\
\hline \multicolumn{4}{|l|}{ Stunting } \\
\hline Yes & $4(12.9)$ & $27(87.1)$ & $*_{\mathrm{p}}=0.788$ \\
\hline No & $23(16.5)$ & $116(83.5)$ & \\
\hline \multicolumn{4}{|l|}{ Wasting } \\
\hline Yes & $9(31.0)$ & $20(69.0)$ & $*_{\mathrm{p}}=0.023$ \\
\hline No & $18(12.8)$ & $123(87.2)$ & \\
\hline \multicolumn{4}{|l|}{ Hospitalization } \\
\hline Yes & $12(35.3)$ & $22(64.7)$ & $\chi^{2}=11.99, \mathrm{p}=0.001$ \\
\hline No & $15(11.0)$ & $121(89.0)$ & \\
\hline \multicolumn{4}{|l|}{ Dyselectrolytaemia } \\
\hline Yes & $8(47.1)$ & $9(52.9)$ & $\chi^{2}=2.06, p=0.151$ \\
\hline No & $4(23.5)$ & $13(76.5)$ & \\
\hline
\end{tabular}

*Fisher's exact test applied. 


\section{Discussion}

The prevalence of VAD observed among children with diarrhoea in this study, being greater than 15 percent, can be said to be of public health significance. ${ }^{19,20}$ Thus, the importance of identifying those at risk among children with diarrhoea, and giving them vitamin A supplements, cannot be over-emphasized.

Despite the presence of VAD and even severe VAD in some of the children in the study, eye signs of VAD were not observed in any of them. Children with severe VAD, in particular, might have been expected to have eye signs. The eye changes, if any, may however be subtle, and thus difficult to observe. The subtle eye changes that occur in the early stages of xerophthalmia may sometimes be visible only through slit-lamp examination. ${ }^{4}$ It is important to realize that many children who are vitamin A deficient will not have eye signs, and many of them may actually have completely normal eyes and vision. ${ }^{21}$ Hence, the absence of eye signs of VAD does not exclude the deficiency of the vitamin.

Increased losses and reduced absorption of vitamin A have been reported to occur during diarrhoea. ${ }^{8-10}$ Worsening of this state may be expected as the duration of diarrhoea lengthens. This expectation was however not substantiated by the present study, as there was no significant relationship between the duration of diarrhoea and serum retinol levels. Differences in the magnitude of vitamin A stores may result in variations in the period of appearance of low serum retinol levels in individual children. Thus, some children with adequate stores may maintain normal serum levels even after significant diarrhoeal losses of the vitamin.

The presence of VAD was significantly associated with hospitalization among the children studied. This finding may indirectly imply a greater severity of diarrhoea in the vitamin A deficient subjects. The fact that the mortality recorded involved a vitamin A deficient child is also worthy of note. Hence, intensifying efforts that are targeted at the reduction of VAD in developing countries may help in reducing the morbidity and mortality associated with childhood diarrhoea.

Children who were underweight, and those who had stunting or wasting, did not have a higher prevalence of VAD than their normal counterparts in the present study. Although, undernutrition is a known risk factor for $\mathrm{VAD},{ }^{4,6,22}$ some children with protein energy malnutrition
(PEM) may be spared if they consume adequate quantities of vitamin A-rich food items. ${ }^{23}$

The World Health Organization had previously recommended vitamin A supplementation for severely undernourished children suffering from diarrhoea. ${ }^{8}$ Routine vitamin A supplementation is however not recommended in the absence of eye signs of VAD, when malnutrition is not severe. Wasting was significantly associated with VAD in the present study. This suggests that the mere presence of wasting in a child with diarrhoea is enough to indicate a high risk of VAD. Affected children will therefore benefit from vitamin A supplementation.

In conclusion, this study shows that wasting and hospitalization are factors that may indicate the presence of VAD in a child with diarrhoea. Thus, it is being recommended that vitamin A supplements be routinely given as part of the treatment for diarrhoea to children who have wasting, especially when they require hospitalization.

\section{Limitation(s) of the study}

Slit-lamp examination of the eyes was not done. This might have detected subtle abnormal eye changes in apparently normal eyes.

This work should be attributed to: Department of Paediatrics, Obafemi Awolowo University Teaching Hospitals Complex, Ile-Ife, Nigeria.

\section{References}

1. WHO. Guideline: Vitamin A supplementation in infants and children 6-59 months of age. Geneva: World Health Organization doc; 2011.

2. WHO. Global health risks: Mortality and burden of disease attributable to selected major risks. Geneva: World Health Organization doc; 2009.

3. UNICEF. The state of the World's children 2014 in numbers. [online]. 2014 [accessed 2014 May 12]; Available from: URL: http://www.unicef.org/publications/ files/SOWC2014_In_Numbers_28_Jan.pdf

4. Sommer A. Vitamin A deficiency and its consequences: A field guide to detection and control. Geneva: World Health Organization doc; 1995.

5. Sommer A, Katz J, Tarwotjo I. Increased risk of respiratory disease and diarrhoea in children with preexisting mild vitamin A deficiency. Am J Clin Nutr 1984; 40: 1090 5. PubMed. https://doi.org/10.1093/ajcn/40.5.1090

6. Edem DO. Vitamin A: a review. Asian J Clin Nutr. 
2009; 1: 65-82. PubMed. https://doi.org/10.3923/ ajen.2009.65.82

7. Bates CJ. Vitamin A. The Lancet. 1995; 345:31-5 PubMed . https://doi.org/10.1016/S0140-6736(95)91157-X

8. WHO. The Treatment of Diarrhoea: A manual for physicians and other senior health workers. WHO/ CDD/SER/80.2; Geneva: World Health Organization doc; 2005.

9. Reddy V, Raghuramulu N, Arunjyoti S, Shivaprakash M, Underwood B. Absorption of vitamin A by children with diarrhoea during treatment with oral rehydration salt solution. Bull World Health Organ. 1986; 65: 721-4.

10. Alvarez JO, Salazar-Lindo E, Kohatsu J, Miranda P, Stephensen CB. Urinary excretion of retinol in children with acute diarrhoea. Am J Clin Nutr. 1995; 61: 1273-6. PubMed . https://doi.org/10.1093/ajcn/61.6.1273

11. Beaton GH, Martorell R, Aronson KJ, Edmonston B, McCabe G, Ross AC. Effectiveness of vitamin A supplementation in the control of young child morbidity and mortality in developing countries. United Nations Nutrition policy discussion paper number 13. Geneva; 1993.

12. Glasziou PP, Mackerras DE. Vitamin A supplementation in infectious diseases. A meta-analysis. BMJ 1993; 306: 366-70. PubMed. https://doi.org/10.1136/ bmj.306.6874.366

13. Barreto ML, Farenzena GG, Fiaccone RL, Santos LM, Assis AM, Araújo MP. Effect of vitamin A supplementation on diarrhoea and acute lower-respiratory-tract infections in young children in Brazil. The Lancet. 1994; 344: 228-31 PubMed. https://doi.org/10.1016/S01406736(94)92998-X

14. Dewan V, Patwari AK, Jain M, Dewan N. A randomized controlled trial of vitamin A supplementation in acute diarrhoea. Indian Paediatr. 1995; 32: 21-5 PubMed . 15. Fischer-Walker CL, Black RE. Micronutrients and diarrhoeal disease. Clin Infect Dis. 2007; 45 (Suppl 1): S73-7. https://doi.org/10.1086/518152

16. Greenbaum L. Deficit therapy. In: Kliegman RM, Behrman RE, Jenson HB, Stanton BF, editors. Nelson Textbook of Pediatrics, 18th ed. Philadelphia: Saunders, Elsevier, 2007. p 313.

17. WHO. WHO child growth standards: methods and development. Geneva: World Health Organization doc; 2006.

18. Oyedeji GA. Socioeconomic and cultural background of hospitalized children in Ilesa. Niger J Paediatr. 1985; 13: 111-8 PubMed .

19. Depee S, Dary O. Biochemical indicators of vitamin A deficiency: serum retinol and serum retinol binding protein. J Nutr. 2002; 132: 2895-901. PubMed .https:// doi.org/10.1093/jn/132.9.2895S

20. WHO. Indicators for assessing vitamin A deficiency and their application in monitoring and evaluating intervention programmes. World Health Organization doc, Geneva; 1996.

21. Gilbert C. The eye signs of vitamin A deficiency. Community Eye Health. 2013; 26: 66-7.

22. Ikekpeazu EJ, Neboh EE, Maduka IC, Ezedigbo AN, Odetunde T. Serum vitamin A levels in children with protein energymalnutrition. Curr Paediatr Res. 2010; 14: 9-13 PubMed .

23. Adelekan DA, Fatusi AO, Fakunle JB. Prevalence of malnutrition and vitamin A deficiency in Nigerian preschool children subsisting on high intake of carotenes. Nutr Health 1997; 12: 17-24. PubMed. https://doi. org/10.1177/026010609701200102 